\title{
PENGARUH PEMBERIAN JUS LIDAH BUAYA TERHADAP PENURUNAN KADAR GULA DARAH PADA PENDERITA DIABETES MELLITUS
}

\author{
Agustina Simamora, ${ }^{1}$ Icceng $^{2}$ \\ INSTITUT KESEHATAN DELI HUSADA DELITUA \\ email: agustinasimamora86@gmail.com
}

\begin{abstract}
Diabetes mellitus is a disease caused by the generation of high blood sugar levels. The treatment of diabetes mellitus is usually with weight control, diet, exercise, and pharmacologis treatment with the drug. One treatment in an alternative way, namely with aloe vera juice can lower blood sugar levels. The purpose of reasearch was to identify the effect of aloe vera juice to decrease blood sugar levels in people with diabetes mellitus at sub village IV village marindal sub district patumbak district deli serdang. The design used is design pre - post without control. The total population is 50 respondents. Sampling techniques used is the formula notoadmojho $10 \%$ with a sample of five samples. Independent variables prior to the giving of aloe vera and the dependent variable was after the administering aloe vera. Analysis of the data used T test. From the results, a significant value pvalue $=0.001$ which means there is the effect of aloe vera juice to decrease blood sugar levels in people with diabetes mellitus. There is a significant reduction in blood sugar levels of $166.373 \mathrm{mg} / \mathrm{dl}$ after administering juice aloe vera 150 gr per day during 7 days.
\end{abstract}

Keywords: Diabetes Mellitus, blood sugar levels, Aloe Vera

\section{PENDAhUluAN}

Kencing manis adalah istilah yang paling sering di ungkapkan masyarakat dalam menyebutkan penyakit Diabetes Milletus, penyakit salah satunya ditandai dengan peningkatan kadar gula darah, dikarenakan pancreas tidak mampu menghasilkan insulin sesuai dengan kebutuhan tubuh, penyakit ini juga dikenal penyakit metabolic. Menurut (Haryono,2012.). Tanda lain dari penderita diabetes milletus adalah banyaknya minum dan banyak kencing. Menurut Lanywati,2011. Diabetes Milletus berasal dari bahasa latin, Diabetes artinya Penerus, dan Melitus artinya Manis.

Diabetes merupakan penyakit dengan gangguan pada pancreas, sehingga pancreas tidak mampu menghasilkan insulin yang merupakn zat untuk mempertahankan kadar gula darah dalam tubuh dalam batas normal, pada penderita diabetes milletus tubuh tidak mampu melepaakan dan mengguakan insulin secara normal, sehingga tubuh membutuhkan tambhan insulin dari luar tubuh untuk membantu keseimbangan glukosa darah. (Chairunnisa, 2012).

Menurut Adrian, (2012) gula dalam darah disebut glukosa yang berasal dari dua sumber yaitu makanan dan yang diproduksi oleh hati. Gula dari makanan yang masuk melalui mulut dicernakan di usus, kemudian diserap ke aliran darah. Dan aliran darah akan membawa glukosa tersebut kedalam otot, jaringan dan sel sebagai sumber energy. Glukosa dan insulin adalah dua hal penting dalam mengatur keseimbangan kadar gula darah ke keseluruh tubuh dan selain itu glukosa juga berguna sebagai bahan bakar dalam jaringan. Insulin berperan dalam proses penyerapan glukosa darah oleh sel dengan cara merangsang hampir semua sel tubuh kecuali sel - sel otak untuk mengambil glukosa dari darah (Sutanto,2013). Gejala klasik diabetes adalah 
adanya rasa haus yang berlebihan, sering kencing terutama malam ahri dan berat badan turun dengan cepat. Bersamaan dengan teasa kabur pada penglihatan, pruiritus, neuropati, banyak minum, luka yang susah sembuh, dan penurunan libido seksual (Syahbudin, 2004).

Diabetes mellitus dibagi menjadi 3 klasifikasi yaitu (1) Diabetes mellitus tergantung insulin (IDDM = insulin dependent diabetes mellitus) yang terjadi pada usia remaja. Lebih dari $90 \%$ sel pankreas yang memproduksi insulin mengalami kerusakan secara permanen, sehingga insulin sedikit diproduksi atau tida langsung. Pada diabetes tipe I kebanyakan pada usia dibawah 30 tahun dan (2) Diabetes mellitus tidak tergantung insulin (NIDDM = non-insulin dependent diabetes mellitus) yang dominan resistensi insulin disertai defesiensi insulin relatif sampai yang terutama defek sekresi insulin disertai resistensi insulin. (3) Diabetes gestasional adalah diabetes yang disebabkan karena kondisi kehamilan. Pada diabetes gestasional, pankreas penderita tidak dapat menghasikan insulin yang cukup untuk mengontrol gula darah pada tingkat yang aman bagi si ibu dan janin (Sutanto,2013).

Menurut suyono 2011, rata-rata penduduk Indonesia dengan prevalensi penderita DM sebanyak 4,6\% dengan jumlah 5,6 juta jiwa dan terus bertambah berdasarkan peningkatan jumlah penduduk Indonesia. Pada tahun 2020 mendatang diperkirakan penduduk usia 20 tahun keatas berjumlah 8,2 juta jiwa atau $4,6 \%$, seangkan dibeberapa negara maju seperti Amerika pada tahun 2006angka prevalensi penderita DM sebanyak $8,3 \%$, dan cina 3,9\%, dikutip dari IDF (International Diabetes Federation). Desa Marindal Dusun IV merupakan Desa yang terletak di Kecamatan Patumbak Kabupaten Deli Serdang. Desa Marindal Dusun IV memiliki jumlah penduduk sebanyak 1383 orang yang terdiri dari 289 kepala keluarga dan memiliki lansia sebanyak 50 orang. Dari 50 orang lansia sebagian besar mengalami Diabetes Mellitus dan pernah melakukan penanganan diabetes secara farmakologis dan non farmakologis. Kandungan kimia lidah buaya antara lain aloin, barbaloin, isobarbaloin, aloe- emodin, aloenin, dan aloesinZat - zat penting dalam lidah buaya antara lain vitamin $A, B_{1}, B_{2}, B_{3}, B_{4}, C, E$, kolin, inositol dan asam folat. Kandungan mineral dalam lidah buaya antara lain kalsium, magnesium, karbohidrat, potassium, sodium, besi , zinc, dan kromium. Kandungan enzim dalam lidah buaya antara lain amylase, catalase, cellulose, caroxypeptidase, carboxybelolase, dan brandykinase, yang semuanya amat penting bagi metabolisme tubuh.

Menurut Paling purung tyas, pada penelitian yang dilakukan pada manusia, pengaruh pemberian sari jus lidah buaya (Aloe Vera) ini menunjukkan perubahan yang signifikan dalam pengontrolan gula darah setelah mengkonsumsi jus lidah buaya dan menghasilkan efek dalam penurunan gula darah. Berdasarkan data yang diperoleh peneliti, peneliti ingin meneliti meneliti tentang pengaruh pemberian jus lidah buaya ( Aloe Vera) terhadap penurunan kadar gula darah pada penderita Diabetes Mellitus di Desa Marindal Dusun IV Kecamatan Patumbak Kabupaten Deli Serdang tahun 2015.

\section{METODOLOGI PENELITIAN}

Penelitian ini menggunakan desain Pre eksperimen dengan pre-test dan post-test dalam satu kelompok (one gruop pretest postest). Populasi dalam penelitian ini adalah umur di atas 45 tahun yang menderita diabetes mellitus di wilayah Marindal Dusun IV sebayak 50 orang. Sampel yang diperoleh peneliti sebanyak 5 responden dengan menggunakan rumus Notoadmojho,2010. Dengan kriteria $>45$ tahun, kadar gula darah $>200 \mathrm{mg} / \mathrm{dl}$,tidak mengkonsumsi obat obatan yang mengendalikan kadar gula darah, dapat diajak berkomunikasi, dan dan tidak dalam keadaan sakit atau dalam perawatan dokter terkait penyakit DM. 
Instrument yang digunakan untuk pengumpulan data adalah penegecekan kadar gula darah dengan menggunakan glukometer dengan data demografi. Analisa data yang dilakukan dengan menggunakan uji dependent $t$-test dengan $a=0,05$ dengan menggunakan komputer untuk menilai apakah ada pengaruh pemberian jus lidah buaya (Aloe Vera) terhadap penurunan kadar gula darah pada penderita Diabetes Mellitus.

\section{HASIL \\ PEMBAHASAN}

PENELITAN

DAN

Karakteristik subjek dalam penelitian ini meliputi usia responden, jenis kelamin responden, pendidikan, pekerjaan, suku, agama, lama menderita DM, dan berat badan responden.

Tabel 1. Karakteristik Umur Responden

\begin{tabular}{|c|c|c|c|}
\hline No & Umur & $\mathrm{F}$ & $\%$ \\
\hline 1 & $45-50$ & 1 & 20 \\
\hline 2 & $51-55$ & 1 & 20 \\
\hline 3 & 56-60 & 2 & 40 \\
\hline 4 & $>60$ & 1 & 20 \\
\hline Tota & & 5 & 100 \\
\hline
\end{tabular}

Bahwa umur responden yang penderita DM yang lebih banyak adalah umur 56-60 tahun sebesar $40 \%$

Tabel 2. Karakteristik Jenis Kelamin Responden

\begin{tabular}{llll}
\hline No & $\begin{array}{c}\text { Jenis } \\
\text { Kelamin }\end{array}$ & $\mathrm{f}$ & $\%$ \\
\hline 1 & Laki - Laki & 1 & 20 \\
\hline 2 & Perempuan & 4 & 80 \\
\hline Total & & & 100 \\
\hline
\end{tabular}

Dari tabel diatas Responden yang berjenis kelamin laki - laki sebanyak 1 orang $(20 \%)$, dan responden yang berjenis kelamin perempuan sebanyak 4 orang $(80 \%)$.

Tabel 3. Karakteristik status perkawinan responden

\begin{tabular}{cccc} 
No & $\begin{array}{c}\text { Status } \\
\text { perkawinan }\end{array}$ & $f$ & $\%$ \\
\hline
\end{tabular}

\begin{tabular}{llll}
\hline 1 & Kawin & 5 & 100 \\
\hline 2 & Tidak Kawin & - & - \\
\hline Total & & 5 & 100
\end{tabular}

Dari tabel diatas Responden yang status perkawinan, Responden yang sudah kawin sebanyak 5 orang $(100 \%)$ dan tidak kawin tidak ada.

Tabel 4. Distribusi pendidikan responden

\begin{tabular}{|c|c|c|c|}
\hline No & Pendidikan & $f$ & $\%$ \\
\hline 1 & SD & 3 & 60 \\
\hline 2 & SMP & 1 & 20 \\
\hline 3 & SMA & 1 & 20 \\
\hline 4 & Perguruan Tinggi & - & - \\
\hline Total & & 5 & 100 \\
\hline
\end{tabular}
berpendidikan SD sebanyak 3 orang (60\%), yang berpendidikan SMP sebanyak 1 orang (20\%), yang berpendidikan SMA sebanyak 1 orang $(20 \%)$, yang berpendidikan Perguruan Tinggi tidak ada.

Tabel 4. Karakteristik berdasarkan suku

\begin{tabular}{|l|l|l|l|}
\hline \multicolumn{1}{|c|}{ No } & \multicolumn{1}{|c|}{ Suku } & \multicolumn{1}{c|}{ f } & \multicolumn{1}{c|}{$\%$} \\
\hline 1 & Batak & 4 & 90 \\
\hline 2 & Aceh & - & - \\
\hline 3 & Minang & - & - \\
\hline 4 & Jawa & - & - \\
\hline 5 & Nias & 1 & 10 \\
\hline Total & & 5 & 100 \\
\hline
\end{tabular}

Dari tabel diatas Responden yang bersuku Batak sebanyak 4 orang (80\%), yang bersuku Nias sebanyak 1 orang (20\%), yang bersuku Aceh tidak ada, yang bersuku Minang tidak ada, yang bersuku Melayu dan Jawa tidak ada.

Tabel 5. Distribusi frekuensi lama menderita DM

\begin{tabular}{|l|l|l|l|}
\hline No & Lama menderita DM & f & $\%$ \\
\hline 1 & $<1$ tahun & - & - \\
\hline 2 & 2 Tahun & 1 & 20 \\
\hline 3 & $<2$ tahun & 4 & 80 \\
\hline Total & & 5 & 100 \\
\hline
\end{tabular}


Dari Tabel Diatas Responden yang lamanya menderita $\mathrm{DM}<1$, tahun tidak ada, 2 tahun sebanyak 1 orang (20\%), dan yang menderita lamanya $>2$ tahun sebanyak 4 orang (80\%).

Tabel 6. Distribusi Frekuensi sebelum pemberian jus lidah buaya

\begin{tabular}{llllll}
\hline $\begin{array}{l}\mathrm{N} \\
\mathrm{o}\end{array}$ & $\begin{array}{l}\text { Variab } \\
\text { el }\end{array}$ & $\begin{array}{l}\text { Mea } \\
\mathrm{n}\end{array}$ & SD & $\begin{array}{l}\text { Min- } \\
\text { Max }\end{array}$ & $\begin{array}{l}95 \% \\
\mathrm{CI}\end{array}$ \\
\hline 1 & KGD 1 & 398. & 81.5 & $328.29-$ & 296. \\
& & 004 & 323 & 535.86 & 7682 \\
& & & 5 & & - \\
& & & & & 499. \\
& & & & & 2398 \\
\hline
\end{tabular}

Menjelaskan tentang kadar gula darah sebelum dilakukan pemberian jus lidah buaya adalah 398,0040 (296,7682 - 499,2398), dengan Standar Deviasi 81,53235. Kadar gula darah terendah sebelum dilakukan pemberian jus lidah buaya adalah 328,29 $\mathrm{mg} / \mathrm{dl}$ dan tertinggi adalah 535,86 mg/dl. Dari hasil estimasi interval dapat disimpulkan bahwa 95\% diyakini bahwa rata - rata kadar gula darah sebelum dilakukan pemberian jus lidah buaya adalah antara 296.7682 499.2398.

Tabel 7.

Distribusi sesudah pemberian jus lidah buaya pada responden

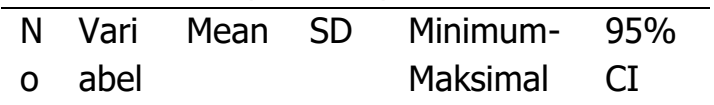

\begin{tabular}{llllll}
\hline 1 & KGD & 231. & 42. & $185-$ & 178. \\
& 2 & 63 & 944 & 290.29 & 3074 \\
& & & 46 & & - \\
& & & & & 284. \\
& & & & & 9526 \\
\hline & & & & & \\
\hline 1 & KGD & 231. & 42. & $185-$ & 178.30 \\
& 2 & 63 & 944 & 290.29 & $74 \quad-$ \\
& & & 46 & & 284.95 \\
& & & & 26 \\
\hline
\end{tabular}

Menjelaskan tentang kadar gula darah sesudah dilakukan pemberian jus lidah buaya adalah Mean 231.63 (178.3074 - 284.9526), dengan Standar Deviasi 42.94446. Kadar gula darah terendah setelah diberikan jus lidah buaya adalah $185 \mathrm{mg} / \mathrm{dl}$ dan tertinggi adalah 290,29 mg/dl. Berdasarkan estimasi interval dapat ditarik kesimpulan bahwa ratarata KGD setelah diberikan jus lidah buaya adalah antara 178.3074 - 284.9526.

Tabel 8. Distribusi frekuensi sebelum dan sesudah pemberian jus lidah buaya pada responden

\begin{tabular}{lllllll}
\hline $\mathrm{N}$ & Varia & Mean & $\mathrm{SD}$ & $\mathrm{SE}$ & $\begin{array}{l}\mathrm{P} . \text { Val } \\
\text { ue }\end{array}$ & $\mathrm{N}$ \\
$\mathrm{O}$ & bel & & & &
\end{tabular}

\begin{tabular}{lllllll}
\hline 1 & KGD1 & 398. & 81.5 & 36.4 & 0.00 & 5 \\
& & 004 & 3235 & 6238 & 1 & \\
& & & & & & \\
2 & KGD2 & 231. & 42.9 & 19.2 & 0.00 & 5 \\
& & 63 & 4446 & 0535 & 1 &
\end{tabular}

Menjelaskan tentang kadar gula darah sebelum dilakukan pemberian jus lidah buaya adalah Mean 398.004, dengan Standar Deviasi 81.53235, Standar Error 36,46238. Sesudah dilakukan pemberian jus lidah buaya adalah 231,63, dengan Standar Deviasi 42,94446 terlihat perbedaan mean antara sebelum dan sesudah dilakukan pemberian jus lidah buaya adalah 166.374. hasil uji statistik didapatkan nilai $p=0,001$, maka dapat disimpulkan ada perbedaan kadar gula darah yang signifikan antara sebelum dan sesudah dilakukan pemberian jus lidah buaya.

Dari penelitian yang dilakukan peneliti terhadap respondens, untuk mengetahui pengaruh pemberian jus lidah buaya terhadap penurunan kadar gula dalam darah pada penderita diabetes mellitus dengan jumlah 5 responden dimana ke-5 responden tersebut dilakukan perlakuan yang sama dengan mengukur kadar gula darah sebelum dan sesudah pemberian jus lidah buaya. Sehingga dapat diketahui bahwa hipotesa penelitian diterima, hal ini dapat dibuktikan 
dengan menggukan uji paired t- test dengan level signifikan $(a=0,05)$ yang menggunakan SPSS diperoleh nilai $p=0,001$ untuk kadar gula darah pada penderita diabetes mellitus.

Dimana terdapat kesesuaian antara peneliti dengan penelitian sebelumnya yang diteliti oleh Panglipuringtyas (2013), yang berjudul pemberian sari lidah buaya terhadap penurunan kadar gula darah acak pada penderita Diabetes Mellitus tipe II yang mendapatkan hasil $p$-value $=0,001$ yang berarti $<0,05$.

Pertiwi (2012), yang mendapatkan hasil p-value $=0,001$ dan pada responden kontrol $p$-value $=0,824$ yang berarti $p>0,05$ yang berjudul Pengaruh pemberian jus lidah buaya terhadap kadar glukosa darah pada wanita prediabetes. Dan pada hasil penelitian yang dilakukan oleh Udo dan Paul (2013), yang mendapatkan hasil $p$-value $=0,001$ yang berjudul Crude Aloe Vera gel Reverses Polyphagia, Polydipsia, Hyperglcemia and Increases Body Weight in Alloxan - Induced Diabetic Rats .

Karena nilai $\mathrm{p}<\mathrm{a}$ maka hipotesa alternative $\mathrm{(Ha}$ ) diterima sedangkan hipotesa nihil ( $\mathrm{Ho}$ ) ditolak yang berarti ada perbedaan secara signifikan perubahan kadar gula darah pada penderita diabetes mellitus antara sebelum dan sesudah melakukan pemberian jus lidah buaya terhadap penurunan kadar gula darah pada penderita diabetes mellitus.

Atau dengan kata lain ada pengaruh pemberian jus lidah buaya terhadap penurunan kadar gula darah pada penderita Diabetes Mellitus di Desa Marindal Dusun IV Kecamatan Patumbak Kabupaten Deli Serdang Tahun 2017.

\section{KESIMPULAN}

Berdasarkan hasil penelitian yang dilakukan pada tanggal 5 Juli 2017 sampai tanggal 12 Juli 2017 terhadap responden yang berusia $>45$ tahun yang penderita Diabetes Mellitus. Terdapat perbedaan antara sebelum dan sesudah dilakukan pemberian jus lidah buaya. Simpulan penelitian ini adalah pemberian jus lidah buaya yang dilakukan secara benar dan rutin bermanfaat terhadap penurunan kadar gula darah pada penderita Diabetes Mellitus. Pemberian jus lidah buaya ini dapat dilakukan sebagai terapi untuk menurunkan kadar gula darah pada penderita Diabetes Mellitus akan bermanfaat bagi setiap orang menderita penyakit.

\section{DAFTAR PUSTAKA}

Adrian, Fellix. 2012. Makanan dan Herbal untuk Penderita Diabetes Mellitus. Jakarta: Penebar Swadaya

Arifin, Jamal. (2015). Intensif Budidaya Lidah Buaya. Yogyakarta: Pustaka Baru Press

Aveonita, Agatha Rhana. (2013). "Effect of Aloe Vera in lowering Bllod Glucose Levels on Diabetes Mellitus. Artike/ penelitian J.Majority. Vol 4 No 2. Faculty of Medicine, Lampung University

Chairunnisa, R. (2012). "Pengaruh Jumlah Pasta Tomat Terhadap Penurunan Kadar Gula Darah Pada Mencit Diabetes". Artikel Penelitian Teknologi Industry Pertanian. Pasca UNAND Fakultas Teknologi Industri Pertanian, hlm 1- 9

Dahlan, Sopiyudin. (2010). Mendiagnosis dan menata Laksana 13 Penyakit Statistik. Jakarta: Sagung Seto

Dempsey, Patrician Ann. Anthur D. Dempsey. (2008). Riset Keperawatan Buku Ajar \& Latihan Edisi 4. Jakarta: EGC

Dharma, Kelana Kusuma. (2011). Metodologi Penelitian Keperawatan Paduan Melaksanakan dan Menerapkan Hasil Penelitian. Cetakan 11,13.Jakarta. CV.Trans Info Media

Haryono, Rudi. Sulis Setianingsih. (2003). Awas musuh- musuh anda setelah usia 40 tahun. Jakarta: Gosyen Publishing

Kurniadi, dr.helmanu. (2014). Stop Diabetes, Hipertensi, Kolesterol, Jantung Koroner. Yogyakarta: Istana Media

Lanywati, dr.Endang. (2011). Diabetes Mellitus Penyakit Kencing Manis. Yogyakarta. Kanisius

Panglipuringtyas, N. Siyoto, S. "Pengaruh Pemberian Sari Lidah Buaya (Aloe Vera) Terhadap Penurunan Kadar Gula Darah Acak Pada Penderita Dm Ii Diwilayah Kerja Puskesmas Karangan 
Kabupaten Trenggalek". STIKes Surya Mitra Husada Kediri

Pertiwi, P.S. (2012). "Pengaruh Pemberian Jus Lidah Buaya Terhadap Kadar Glukosa Darah Puasa Pada Wanita Prediabetes". Artikel penelitan program studi ilmu gizi fakultas kedokteran universitas diponegoro semarang. 1-5

Pudiastuti, Ratna Dewi. (2016). Penyakitpenyakit mematikan. Yogyakarta: Nuha Medika

Soegondo, S. Soewondo Pradana. Imam Subekti. (2009). Penatalaksanaan Diabetes Mellitus Terpadu edisi kedua. Jakarta: FKUI

Steencamp, V Stewart MJ. Medikal Application And Toxicological Activities Of Aloe Vera Product. Forensic Patology Research 2007: 27 773-5

Sutanto, Teguh. (2013). Diabetes Deteksi,Pencegahan, Pengobatan. Yogyakarta: Buku Pintar 